\title{
1 Estimating crop yield using a satellite-based light use efficiency model
}

2 Wenping Yuan ${ }^{1}$, Yang Chen ${ }^{1}$, Jiangzhou Xia ${ }^{1}$, Wenjie Dong ${ }^{*}$, Vincenzo Magliulo ${ }^{2}$, Eddy Moors ${ }^{3}$,

3 Jørgen Eivind Olesen ${ }^{4}$, Haicheng Zhang ${ }^{1}$

$4 \quad{ }^{1}$ State Key Laboratory of Earth Surface Processes and Resource Ecology, Beijing Normal

5 University, Beijing 100875, China

$6 \quad{ }^{2}$ National Research Council, Institute for Agricultural and Forest Systems, 80040 Ercolano, Napoli,

$7 \quad$ Italy

$8 \quad{ }^{3}$ Wageningen UR, Alterra, Earth System Science and Climate Change Group, PO Box 47, 6700

9 AA Wageningen, The Netherlands

$10{ }^{4}$ Department of Agroecology, Aarhus University, DK-8830 Tjele, Denmark

12 Abstract Satellite-based techniques that provide temporally and spatially continuous

information over vegetated surfaces have become increasingly important in monitoring the global

agriculture yield. In this study, we examine the performance of a light use efficiency model

(EC-LUE) for simulating the Gross Primary Production (GPP) and yield of crops. The EC-LUE

model can explain on average approximately $90 \%$ of the variability in GPP for 36 FLUXNET sites

17 globally. The results indicate that a universal set of parameters, independent of crop species

(except for C4 crops), can be adopted in the EC-LUE model for simulating crops' GPP. At both

irrigated and rainfed sites, the EC-LUE model exhibits a similar level of performance. However,

\footnotetext{
* Corresponding author: dongwj@bnu.edu.cn (Wenjie Dong), yuanwpen@ 126.com (Wenping Yuan) 
crop yield estimations from satellite-based methods.

Key words: Light use efficiency; EC-LUE; Gross primary production; Crop yield

24

25

\section{Introduction}

Approximately $12 \%$ of the Earth's land surface is presently represented by cultivated cropland, which supplies the great part of human food production. Sustained world population growth, rising meat and dairy consumption and expanding biofuel use are exerting increasing pressure on global agriculture (Ray et al., 2012). Global food production, however, is and will be significantly affected by climate change (Parry et al., 2004; Schmidhuber and Tubiello, 2007). In this perspective, crop production monitoring and forecasting is of fundamental importance for agricultural management, food security threats, food trade policy and carbon cycle research (Tilman et al., 2011).

Remotely sensed data provides temporally and spatially continuous information over vegetated surfaces and is useful for accurately monitoring cropland yield and spatial patterns.

Generally, there are two approaches for yield estimation using remote sensing data. The first method includes biophysical crop-simulation models that retrieve crop growth parameters from remotely sensed data, which are used as inputs to calibrate and drive the models (Brisson et al., 1998). The main drawback of such models is that they typically require numerous crop-specific inputs such as soil characteristics, management practices, agro-meteorological data and planting dates to simulate crop growth and development through the crop cycle (Moriondo et al., 2007).

Such crop-simulation models include CERES (Ritchie and Otter, 1985), WOFOST (van Diepen et al., 1989) and CROPSYST (van Evert and Campbell, 1994). The second scheme includes 
statistical regression-based methods, which are the most commonly used remote sensing-based approaches (Wall et al., 2008). These are based on empirical relationships between historic yields and reflectance-based vegetation indices. They are typically straightforward to implement and do not require numerous inputs. A main drawback of empirically based approaches is that the relationships between yield and reflectance are typically localized and are not easily extendable to other areas (Doraiswamy et al., 2003; Moriondo et al., 2007).

Satellite-based light use efficiency (LUE) models are an alternative approach that makes it possible to accurately estimate crop yield, because they can successfully estimate the vegetation's gross primary production (GPP), which is at the basis of the ecosystem's carbon biogeochemical cycle and the main variable determining crop yield. The LUE models build upon the assumption that ecosystem GPP is directly related to the absorbed photosynthetically active radiation (APAR) through LUE (Monteith 1972; Monteith 1977). Actual LUE may be reduced below its theoretical potential value by environmental stresses such as low temperatures or water shortages (Landsberg, 1986; Goerner et al., 2009,). Some studies have evaluated LUE models at regional and global scales in major ecosystem types (Potter et al., 1993; Turner et al., 2006; Huntzinger et al., 2012; Yuan et al., 2012; Raczka et al., 2013; Cai et al., 2014). In recent years, several studies have used the LUE models to address the spatial and temporal patterns of cropland vegetation production (Chen et al., 2014) and to simulate crop yield over large areas (Xin et al., 2013). On the other hand, some authors examined the capability of LUE models to estimate crop yield and demonstrated large uncertainties. For example, based on the MODIS-GPP products (MOD17), Reeves et al. (2005) found a weak correlation between GPP estimates and the national agricultural yield data at the county level for the states of Montana and 
North Dakota in the United States, and highlighted the need to use crop-specific model parameters.

Moreover, the model performance for simulating crop yield has never been evaluated at the site

scale. Previous studies often examined model performance over large regions by comparing outputs with regional crop inventory data (Xin et al., 2013; Li et al., 2014). The uncertainties from model inputs, which are needed for regional estimates, will hinder the judgment of model performance. Li et al. (2014) found the misclassification of cropland from a land cover product is one of the major causes of bias in the NPP estimates of cropland in the midwestern United States. This study aims to examine the performance of a LUE model (i.e., EC-LUE, Yuan et al., 2007) for the prediction of crop biomass and yield production, over multiple crop species globally.

The overarching goals of this study are to (1) examine the model performance for vegetative primary production across various crop types and management, (2) assess the possibility for simulating crop yield from crop vegetation production estimates, and (3) investigate the most relevant processes for crop yield simulations based on the LUE models.

\section{Model and Data}

\subsection{EC-LUE model}

Yuan et al. (2007, 2010) developed the Eddy Covariance-Light Use Efficiency (EC-LUE)

model to simulate daily vegetation GPP. The EC-LUE model is driven by only four variables: the Normalized Difference Vegetation Index (NDVI), Photosynthetically Active Radiation (PAR), air temperature $(T)$, and the Bowen ratio of sensible to latent heat flux. The EC-LUE model has the great advantage to map daily GPP over large areas because the potential LUE is invariant across various land cover types (Yuan et al., 2014b). Previous study indicated that a universal of set of 
parameters, which is independent of vegetation cover type and characteristics can be adopted in

EC-LUE model (Yuan et al., 2014b). Availability of this well tested and universal set of parameters would help to improve the accuracy and applicability of LUE models invarious biomes and geographic regions.

$$
\text { The model equations are as follows: }
$$

$$
\begin{aligned}
& G P P=P A R \times f P A R \times \varepsilon_{\max } \times \operatorname{Min}\left(T_{s}, W_{S E F}\right) \\
& f P A R=1.24 \times N D V I-0.168 \\
& T_{s}=\frac{\left(T-T_{\min }\right) \times\left(T-T_{\max }\right)}{\left(\left(T-T_{\min }\right) \times\left(T-T_{\max }\right)-\left(T-T_{o p t}\right)^{2}\right)} \\
& W_{S E F}=\frac{L E}{R_{n}}
\end{aligned}
$$

where fPAR is the fraction of intercepted incident PAR. $\varepsilon_{\max }$ is the potential light use efficiency without environmental stress (2.14 $\mathrm{g} \mathrm{C} \mathrm{m}^{-2} \mathrm{MJ}^{-1}$ APAR). Min denotes the minimum values of $T_{s}$ and $W_{S E F}$, (it is assumed that the impacts of temperature and moisture follow Liebig's Law, so that LUE is only affected by the most limiting factor at any given time). $T_{\min }, T_{\max }$ and $T_{\text {opt }}$ are the minimum, maximum and optimum air temperatures $\left({ }^{\circ} \mathrm{C}\right)$ for photosynthetic activity, respectively. If the air temperature falls below $T_{\min }$ or increases beyond $T_{\max }, T_{s}$ is set to zero. In this study, $T_{\min }$ and $T_{\max }$ were set to 0 and $40^{\circ} \mathrm{C}$ (Yuan et al., 2007), respectively, while $T_{\text {opt }}$ was determined using nonlinear optimization to be $21^{\circ} \mathrm{C}$ (Yuan et al., 2007). $L E$ is the daily latent heat flux $\left(\mathrm{MJ} \mathrm{m}^{-2}\right.$ ), which is estimated using the revised RS-PM (Remote Sensing-Penman Monteith) model (Yuan et al., 2010). $R_{n}$ is the daily net radiation $\left(\mathrm{MJ} \mathrm{m}^{-2}\right)$. 

examine the performance of the EC-LUE model (Table 1). These sites covered several dominant cropland ecosystem types (Table 1). EC data were obtained from the websites: FLUXNET (http://www.fluxdata.org), HiWATER (http://westdc.westgis.ac.cn/hiwater) (Li et al., 2013), and AsiaFlux (http://www.asiaflux.net). Supplementary information on the vegetation, climate and soil at each site was also available at the above web sites. Half-hourly or hourly averaged PAR, T and friction velocity $\left(\mathrm{u}^{*}\right)$ were used along with Net ecosystem $\mathrm{CO}_{2}$ exchange (NEE) in this study. FLUXNET datasets that were gap-filled by site investigators were used directly for this study (i.e., the LaThuile database) (Agarwal et al., 2010).

$<<$ Table $1>>$ procedures were used to fill data gaps (Yuan et al., 2014a): nonlinear regression relationships were fitted between the measured fluxes and controlling environmental variables (air temperature, PAR) and subsequently used to fill the missing values using a 15-day moving window. The van't Hoff equation was used to estimate missing night time NEE $\left(F_{c, \text { night }}\right)$ (Lloyd and Taylor, 1994):

$$
F_{c, d a y}=\frac{\alpha \times \mathrm{PAR} \times F_{G P P, s a t}}{F_{G P P, s a t}+\alpha \times \mathrm{PAR}}-F_{R E, d a y}
$$


where $F_{G P P \text { sat }}$ (the GPP at saturating light) and $\alpha$ (the initial slope of the light response function) are empirically estimated coefficients, and $F_{R E, d a y}$ (ecosystem respiration) was estimated by the extrapolation of Eq. (5) using the daytime air temperature. The daily NEE, ecosystem respiration $(R e)$, and meteorological variables were averaged based on half-hourly or hourly values, and the daily values were flagged as missing when more than $20 \%$ of the data for a given day was lacking; otherwise, the daily values were calculated by multiplying the averaged half-hourly or hourly rate by 24 hours. The GPP was calculated as the sum of the NEE and Re. Based on the daily dataset, the 8-day GPP mean value could be calculated. If more than 2 days of daily data were missing within a given 8-day period, the 8-day value was indicated as missing.

We adapted the harvest index methods (Prince et al., 2001) to estimate crop yield using the following equations:

$$
\text { Yield }=G P P \times A R \times H I \times R S
$$

where Yield is the crop yield $\left(\mathrm{g} \mathrm{C} \mathrm{m}^{-2} \mathrm{yr}^{-1}\right) . A R$ is the autotrophic respiration proportion accounting for GPP (0.53) (Waring et al., 1998), and GPP $\times A R$ indicates the net primary production (NPP) (g $\left.\mathrm{C} \mathrm{m}^{-2} \mathrm{yr}^{-1}\right) . H I$ refers to the harvest index, a standard measure of the proportion of total crop aboveground biomass allocated to the economic yield of the plant (Donald and Hamblin, 1976;

Hay, 1995). The carbon allocation coefficient, $R S$, indicates the ratio of aboveground NPP to the total NPP. This study uses the $H I$ and $R S$ values collected by Monfreda et al. (2008) for various crop types. A constant mean carbon content of $0.45 \mathrm{~g} \mathrm{C} \mathrm{g} \mathrm{dry} \mathrm{matter}{ }^{-1}$ was used to derive crop yield from economic yield ( $\mathrm{g}$ dry matter). In this study, we used both of estimated GPP based on EC measurements and simulated GPP of EC-LUE to calculate crop yield, and compared them with yield observations. The former comparison is to evaluate the performance of Eq. (7) to estimate 
147 yield, and the latter comparison can indicate the EC-LUE model performance for estimating crop

148 yield. error (BIAS, difference between the mean observations and simulations).

\section{Results}


sites. At almost all sites where maize was grown, the EC-LUE model strongly underestimated GPP when the original $\varepsilon_{\max }$ model parameter value was used (Fig. 2). The original $\varepsilon_{\max }$ was calibrated at twelve EC towers with dominated by C3 grasses and trees (Yuan et al., 2007). We therefore calibrated the potential LUE over all of the EC sites where maize was planted, and the derived parameter was equal to $2.84 \mathrm{~g} \mathrm{C} \mathrm{MJ}^{-1}$. Substituting the calibrated parameter value in the equation substantially improved the model performance for maize (Fig. 2), and the EC-LUE model explained $90 \%$ of the GPP variations across all 36 sites (Fig. 2). The EC-LUE model performed very well under both irrigated (16 sites) and rainfed (9 sites) conditions (see table 2), since no significant differences in GPP simulations could be detected (Fig. 3).

$<<$ Figure 2>>

$<<$ Figure 3>>

Using the yield observations collected at 12 sites, we examined the model performance for simulating crop yield. The model explained approximately $61 \%$ of the variation in crop yield over a total of 26 site-years (Fig. 4a). However, large differences between the predicted yield and observations still existed at a few sites. The model underestimated yield between $61 \%$ and $32 \%$ at several sites (e.g., US-Ne3 (2001), DE-Geb, CH-Oe2 and US-Ne1) (data not shown). On the other side, predictions were higher than those observed for the crop yield at US-Ne3 (2003), FR-Aur and BE-Lon with RPE values that varied from $34 \%$ to $55 \%$. Moreover, the results showed the errors of simulated yield using estimated GPP based on EC measurements, which implied the uncertainties of the harvest index method for estimating crop yield (Fig. 4b).

$<<$ Figure 4>> 
189

190

191

192

193

194

\section{Discussion}

\subsection{Model performance for simulating GPP}

The successful model validation at 36 EC crop sites globally suggested that the EC-LUE model was robust and reliable for estimating GPP across cropland ecosystems. The results showed that the EC-LUE model did not produce significant predictive errors of the GPP across the majority of all investigated sites, only underestimating the GPP of the C4 crops. Specifically, the EC-LUE model uses a universal set of parameters (i.e., potential light use efficiency, $\varepsilon_{\text {max }}$ ), which are independent of the vegetation cover type, that makes it easy to map the GPP over large areas (Yuan et al., 2014b). Conversely, other LUE models also require vegetation-specific model parameters that might limit model applicability. For example, a recent study found that the estimated potential LUE of the CASA model varied substantially over 12 agricultural eddy flux measurement sites in North America and Europe (Chen et al., 2011).

Theoretically, the potential light use efficiency of C4 crops is larger compared with that of C3 plants (DeLucia et al., 2014). The parameters of the EC-LUE model, however, were originally calibrated for $\mathrm{C} 3$ plant dominant ecosystems, which was the major cause for the underestimation of the GPP of the C4 crops. Monfreda et al. (2008) showed that although the C4 crops are few (maize, sorghum, millet, sugarcane, and some grasses), they comprise 3.2 million $\mathrm{km}^{2}$, which is a disproportionate $24 \%$ of the entire harvested area and $17 \%$ of all $\mathrm{C} 4$ vegetation. Therefore, it is of great importance to improve the model performance for C4 crops. Our results showed that a specific potential LUE could be derived for $\mathrm{C} 4$ crops, to improve the performance of the EC-LUE model. This implies that it is necessary to use a spatial distribution map of C3 and 
C4 crops to improve the accuracy in quantifying crop GPP at a global scale.

For cropland ecosystems, strong agricultural management, such as fertilization,

irrigation and crop protection, impacts photosynthetic capacity by affecting leaf $\mathrm{CO}_{2}$ exchange

rate as well as green leaf area index. Validation showed the ability of the model to simulate GPP across different crops, climatic conditions and field management. This results from the fact that the remotely sensed vegetation index effectively integrates the photosynthetic capacity, also across different soil moisture and nutrient limitation conditions (Yao et al., 2010). A previous study compared the vegetation index over three adjacent sites at the University of Nebraska-Lincoln's Agricultural Research and Development Center near Mead, Nebraska, USA. The results showed that the vegetation index was lower at a rainfed site than at the irrigated site, and the measured difference was a quantitative measure of the impact of irrigation on crop canopy development (Kalfas et al., 2011).

\subsection{Challenges for simulating crop yield}

This study used the carbon allocation coefficient and harvest index to simulate crop yield based on GPP estimations (see method). The former indicates the ratio of aboveground NPP to total NPP and the latter the weight of the harvested product as a percentage of the total plant weight. In this study, we used a constant carbon allocation coefficient and harvest index for each species (Monfreda et al., 2008) and did not take into account temporal or spatial variations. In general, resource limitations such as water and nutrient deficits can enhance translocation from source to sink organs (Temperton et al., 2003), increasing resource use efficiency (Yuan et al., 2006; Ikegami and Whigham, 2007; Matzek, 2011). Xu et al. (2007) showed that a marked 
increase in the root-to-shoot ratio of biomass/carbon under drought conditions allowed for the absorption of more soil water. Similar effects have been observed across conditions of varying nutrient supply (Chirinda et al., 2012).

With global climatic change, water availability is expected to become increasingly important as a key controlling factor for crop yield, especially considering that globally only $18 \%$ of the cultivated area is irrigated (FAO, 2005) and the frequency and severity of summer droughts are expected to increase (IPCC, 2013). In the United States, for example, the average crop yields of irrigated farms exceeded, in 2003, the corresponding yields of dryland farms by $15 \%$ for soybeans, $30 \%$ for maize, $99 \%$ for barley, and $118 \%$ for wheat (Veneman et al., 2004). In this study, we found that the impact of water availability cannot be ignored for simulating crop yield, as it strongly determined the carbon allocation to seeds. Figure 5 compares the ratios of the crop yield and observed GPP between the irrigated and rainfed sites at the University of Nebraska-Lincoln's Agricultural Research and Development Center near Mead, Nebraska, USA.

The results show the ratio of the observed GPP is approximately 1, but the ratios of the crop yield are much lower than those of the GPP, which indicates the strong impact of soil moisture on carbon allocation to the seeds.

$<<$ Figure 5>>

In addition to the carbon allocation coefficient, the harvest index is another important factor for determining the accuracy of yield simulations. As the Fig. $4 \mathrm{~b}$ showed the uncertainties in simulated crop yield using estimated GPP based on EC measurements. This study used the harvest index values proposed by Monfreda et al. (2008). However, harvest index is known to vary with cultivars and growing conditions (Hay and Gilbert, 2001). López-Castaneda and 
253

254

255

256

257

258

259

260

261

262

263

264

265

266

267

268

269

270

271

Richards (1994) found a negative correlation between the harvest index and number of days to anthesis in barley, wheat, triticale, and oats under Mediterranean conditions; earlier flowering in that environment allows for grain filling to occur before both the temperature and vapor pressure deficit increase. Much of the increase in wheat yield over the past century stems from the selection for a higher harvest index (Sinclair, 1998). Another study found that the harvest indices were not highly heritable and fluctuated with season, management, and environmental conditions, in a survey of the tropical varieties of maize in Mexico and Malawi (Hay and Gilbert, 2001). The harvest index is also decreased by other yield limiting factors, such as pests and diseases (Olesen et al., 2000).

\section{Conclusions}

Model validation at 36 eddy covariance sites globally suggested that the EC-LUE model was robust and reliable for simulating the vegetative primary production of cropland. The model may be a good candidate for mapping the GPP of regional and global cropland because it is independent of crop (except for $\mathrm{C} 4$ species) and all driving variables can be retrieved from satellites or standard weather observation networks. Moreover, the EC-LUE model can be used to simulate crop yield from GPP estimates based on the harvest index. However, large biases of yield estimates still exist because of uncertainties for the harvest index and carbon allocation.

\section{Acknowledgments}

This study was supported by the National Science Foundation for Excellent Young 
273

274

275

276

277

278

279

280

281

282

283

284

285

286

287

Scholars of China (41322005), the National High Technology Research and Development

Program of China (863 Program) (2013AA122003, 2013AA122800), Program for New Century

Excellent Talents in University (NCET-12-0060) and National Natural Science Foundation of

China(91125002). This work used eddy covariance data acquired by the FLUXNET community.

We acknowledge the financial support to the eddy covariance data harmonization provided by

GHG-Europe, FAO-GTOS-TCO, iLEAPS, Max Planck Institute for Biogeochemistry, National

Science Foundation, University of Tuscia, Université Laval, Environment Canada and US

Department of Energy and the database development and technical support from Berkeley Water

Center, Lawrence Berkeley National Laboratory, Microsoft Research eScience, Oak Ridge

National Laboratory, University of California - Berkeley and the University of Virginia. We also acknowledge the Coordinated Observations and Integrated Research over Arid and Semi-arid

China (COIRAS) (lead by Key Laboratory of Regional Climate-Environment Research for the Temperate East Asia (RECTEA)).

\section{References}

Agarwal, D.A., Humphrey, M., Beekwilder, N.F., Jackson, K.R., Goode, M.M., \& Lngen C.V. 2010. A data-centered collaboration portal to support global carbon-flux analysis. Concurrency and Computation: Practice and Experience, 22, 2323-2334.

Anthoni, P.M., Freibauer, A., Kolle, O., \& Schulze, E.D. 2004. Winter wheat carbon exchange in Thuringia, Germany. Agricultural and Forest Meteorology, 121, 55-67.

Aubinet, M., Moureaux, C., Bodson, B., Dufranne, D., Heinesch, B., Suleau, M., Vancutsem, F., \& 
Vilret, A. 2009. Carbon sequestration by a crop over a 4-year sugar beet/winter wheat/seed potato/winter wheat rotation cycle. Agricultural and Forest Meteorology, $149,407-418$.

Béziat, P., Ceschia, E., \& Dedieu, G. 2009. Carbon balance of a three crop succession over two cropland sites in South West France. Agricultural and Forest Meteorology, 149, 1628-1645.

Brisson, N., Mary, B., Ripoche, D., Jeuffroy, M.H., Ruget, F., Nicoullaud, B., Gate, P., et al. 1998. STICS: a generic model for the simulation of crops and their water and nitrogen balances. I. Theory and parameterization applied to wheat and corn. Agronomie, 18 (5-6), 311-346.

Cai, W.W., Yuan, W.P., Liang, S.L., Zhang, X.T., Dong, W.J., Xia, J.Z., Fu, Y., Chen, Y., Liu, D., \& Zhang, Q. 2014. Improved estimations of gross primary production using satellite-derived photosynthetically active radiation. Journal of Geophysical Research: Biogeosciences, 119 (1), 110-123.

Chen, T., van der Werf, G.R., Gobron, N., Moors, E.J. \& Dolman, A.J. 2014. Global cropland monthly gross primary production in the year 2000. Biogeosciences, 11, 3871-3880.

Chen, T.X., van der Werf, G.R., Dolman, A.J. \& Groenendijk, M. 2011. Evaluation of cropland maximum light use efficiency using eddy flux measurements in North America and Europe. Geophysical Research Letters, 38, L14707.

Chirinda, N., Olesen, J.E. \& Porter, J.R. 2012. Root carbon input in organic and inor-ganic fertilizer-based systems. Plant and Soil 359, 321-333.

Dietiker, D., Buchmann, N., \& Eugster, W. 2010. Testing the ability of the DNDC model to predict 

Environment, 139, 396-401.

Donald, C.M., \& Hamblin, J. 1976. The biological yield and harvest index of cereals as agronomic and plant breeding criteria. Advances in Agronomy, 28, 361-415.

Doraiswamy, P. C., Moulin, S., \& Cook, P. W. 2003. Crop yield assessment from remote sensing. Photogrammetric Engineering and Remote Sensing, 69, 665 - 674.

DeLucia, E.H., Gomez-Casanovas, N., Greenberg, J.A., Hudiburg, T.W., Kantola, I.B., Long, S.P. et al. 2014. The theoretical limit to plant productivity. Environmental Science and Technology, 48, 9471-9477.

Eugster, W., Moffat, A.M., Ceschia, E. 2010. Management effects on European cropland respiration. Agriculture Ecosystems and Environment, 139, 346-362.

Falge, E., Baldocchi, D., Olson, R., Anthoni, P., Aubinet, M., Bernhofer, C., et al. 2001. Gap filling strategies for defensible annual sums of net ecosystem exchange. Agricultural and Forest Meteorology, 107, 43-69.

Food and Agriculture Organization of the United Nations (FAO) 2005. FAO Stat. FAO Statistical Databases. Available online at. http://faostat.fao.org/

Hay, R.K. 1995. Harvest index: a review of its use in plant breeding and crop physiology. Annals of Applied Biology, 126, 197-216.

Hay, R. K. M., \& Gilbert, R.A. 2001. Variation in the harvest index of tropical maize: evaluation of recent evidence from Mexico and Malawi. Annals of Applied Biology, 138(1), 103-109.

Huntzinger, D.N., Post, W.M., Wei, Y., Michalak, A.M., West, T.O., Jacobson, A.R., et al. 2012. 
North American Carbon Program (NACP) regional interim synthesis: Terrestrial biospheric model intercomparison. Ecological Modelling, 232, 144-157.

Ikegami, M., Whigham, D.F., \& Werger, M.J.A. 2007. Responses of rhizome length and ramet production to resource availability in the clonal sedge Scirpus olneyi A. Gray. Plant Ecology, 189, 247-259.

IPCC 2013. Climate Change 2013: The Physical Science Basis. Contribution of Working Group I to the Fifth Assessment Report of the Intergovernmental Panel on Climate Change. In Stocker, T.F., D. Qin, G.-K. Plattner, M. Tignor, S.K. Allen, J. Boschung, A. Nauels, Y. Xia, V. Bex and P.M. Midgley (Eds.). Cambridge \& United Kingdom and New York: Cambridge University Press.

Kalfas, J.L., Xiao, X.M., Vanegas, D.X., Verma, S.B., \& Suyker, A.E. 2011. Modeling gross primary production of irrigated and rain-fed maize using MODIS imagery and $\mathrm{CO}_{2}$ flux tower data. Agricultural and Forest Meteorology, 151, 1514-1528.

Landsberg, J. J. 1986. Physiological Ecology of Forest Production. London: Academic Press, 352.

Monteith, J.L. 1972. Solar radiation and productivity in tropical ecosystems. J. Appl. Ecol. 9, $747-766$.

Monteith, J.L. 1977. Climate and the efficiency of crop production in Britain. Philos. Trans. R. Soc. Lond., Ser. B. 281, 277-294.

Goerner, A., Reichstein, M., \& Rambal, S. 2009. Tracking seasonal drought effects on ecosystem light use efficiency with satellite-based PRI in a Mediterranean forest. Remote Sensing of Environment, 113, 1101-1111.

Lehuger, S., Gabrielle, B., Cellier, P., Loubet, B., Roche, R., Béziat, P., Ceschia, E., \& Wattenbach, 
M. 2010. Predicting the net carbon exchanges of crop rotations in Europe with an agro-ecosystem model. Agriculture, Ecosystems and Environment, 139, 384-395.

Li, X., Cheng, G.D., Liu, S.M., Xiao, Q., Ma, M.G., Jin, R., Che, T., Liu, Q.H., Wang, W.Z., et al. 2013. Heihe Watershed Allied Telemetry Experimental Research (HiWATER): scientific objectives and experimental design. Bulletin of the American Meteorological Society, 94, 1145-1160.

Li, Z.P., Liu, S.G., Tan, Z.X., Bliss, N.B., Young, C.J., West, T.O., \& Ogle, S. M. 2014. Comparing cropland net primary production estimates from inventory, a satellite-based model, and a process-based model in the Midwest of the United States. Ecological Modelling, 277, 1-12.

Liu, S.M., Xu, Z.W., Zhu, Z.L., Jia, Z.Z., \& Zhu, M.J. 2013. Measurements of evapotranspiration from eddy-covariance systems and large aperture scintillometers in the Hai River Basin, China. Journal of Hydrology, 487, 24-38.

Lloyd, L. \& Taylor, J.A. 1994. On the temperature dependence of soil respiration. Functional Ecology, 8, 315-323.

López-Castañeda, C., \& Richards, R.A. 1994. Variation in temperate cereals in rainfed environments I. Grain yield, biomass and agronomic characteristics. Field Crops Research, 37, 51-62.

Matzek, V. 2011. Superior performance and nutrient-use efficiency of invasive plants over non-invasive congeners in a resource-limited environment. Biological Invasions, 13, 3005-3014.

Meijide, A., Manca, G., Goded, I., Magliulo, V., di Tommasi, P., Seufert, G., \& Cescatti, A. 2011. 

Seasonal trends and environmental controls of methane emissions in a rice paddy field in Northern Italy. Biogeosciences, 8, 3809-3821.

Meyers, T. P., \& Hollinger, S. E. 2004. An assessment of storage terms in the surface energy balance of maize and soybean. Agricultural and Forest Meteorology, 125, 105-115.

Monfreda, C., Ramankutty, N., \& Foley, J.A. 2008. Farming the planet: 2. Geographic distribution of crop areas, yields, physiological types, and net primary production in the year 2000 . Global Biogeochemical Cycles, 22, GB1022.

Moors, E.J., Jacobs, C., Jans, W., Supit, I., Kutsch, W. L., Bernhofer, C., et al. 2010. Variability in carbon exchange of European croplands. Agriculture, Ecosystems and Environment, 139, $325-335$.

Moriondo, M., Maselli, F., \& Bindi, M. 2007. A simple model of regional wheat yield based on NDVI data. European Journal of Agronomy, 26 (3), 266-274.

Olesen, J.E., Mortensen, J.V., Jørgensen, L.N. \& Andersen, M.N. 2000. Irrigation strat-egy, nitrogen application and fungicide control in winter wheat on a sandy soil. I. Yield, yield components and nitrogen uptake. Journal of Agricultural Science, Cambridge 134, 1-11.

Parry, M.L., Rosenzweig, C., Iglesias, A., Livermore, M., \& Fischer, G. 2004. Effects of climate change on global food production under SRES emissions and socio-economic scenarios. Global Environmental Change, 14, 53-67.

Potter, C.S., Randerson, J.T., Field, C.B., Matson, P. A., Vitousek, P.M., Mooney, H.A., \& Klooster, S.A. 1993. Terrestrial ecosystem production: A process model based on global satellite and surface data. Global Biogeochemical Cycles, 7 (4), 811-841.

Prince, S., Haskett, J., Steininger, M., Strand, H., \& Wright, R. 2001. Net primary production of 
404

405

406

407

408

409

410

411

412

413

414

415

416

417

418

419

420

421

422

423

424

425

U.S. midwest croplands from agricultural harvest yield data. Ecological Applications, 11(4), 1194-1205.

Raczka, B.M., Davis, K.J., Huntzinger, D.N., Neilson, R., Poulter, B., Richardson, A., et al. 2013. Evaluation of continental carbon cycle simulations with North American flux tower observations. Ecological Monographs, 83, 531-556.

Ray, D.K., Ramankutty, N., Mueller, N.D., West, P.C. \& Foley, J.A. 2012. Recent patterns of crop yield growth and stagnation. Nature Communications, 3, 1293.

Reeves, M.C., Zhao, M. \& Running, S.W. 2005. Usefulness and limits of MODIS GPP for estimating wheat yield. International Journal of Remote Sensing, 26, 1403-1421.

Ritchie, J.R. \& Otter, S. 1985. Description and performance of CERES-Wheat: a user-oriented wheat yield model. United States Department of Agriculture, Agricultural Research Service, 38, 159-175.

Schmidhuber, J., \& Tubiello, F.N. 2007. Global food security under climate change. Proceedings of the National Acaddemy of Sciences of the United States of America, 104, 19703-19708.

Sinclair, R.S. 1998. Historical changes in harvest index and crop nitrogen accumulation. Crop Science, 38, 638-643.

Temperton, V.M., Grayston, S.J., Jackson, G., Barton, C.V.M., Millard, P. \& Jarvis, P.G. 2003.Effects of elevated carbon dioxide concentration on growth and nitrogen fixation in Alnus glutinosa in a long-term field experiment. Tree Physiology, 23 (15), 1051-1059

Tilman, D, Balzer, C, Hill, J, Befort, BL. 2011. Global food demand and the sustainable intensification of agriculture. Proceedings of the National Acaddemy of Sciences of the 
Turner, D.P., Ritts, W.D., Styles, J.M., Yang, Z., Cohen, W.B., Law, B.E., \& Thornton, P.E. 2006. A diagnostic carbon flux model to monitor the effects of disturbance and interannual variation in climate on regional NEP. Tellus B, 58(5), 476-490.

Van Depen, C.A., Wolf, J., van Keulen, H., \& Rappoldt, C. 1989. WOFOST: a simulation model of crop production. Soil Use and Management, 5(1), 16-24.

Van Evert, F. K., \& Campbell, G.S. 1994. CropSyst: A Collection of Object-Oriented Simulation Models of Agricultural Systems. Agronomy Journal, 86 (2), 325-331.

Veneman, A.M., Jen, J.J., \& Bosecker, R.R. 2004. 2002 Census of Agriculture - Farm and Ranch Irrigation Survey (2003), United States Department of Agriculture (USDA), National Agricultural Statistics Survey (NASS), http://www.usda.gov/nass/.

Verma, S. B., Dobermann, A., Cassman, K. G., Walters, D. T., Knops, J. M., Arkebauer, T. J., et al. 2005. Annual carbon dioxide exchange in irrigated and rainfed maize-based agroecosystems. Agricultural and Forest Meteorology, 131, 77-96.

Waring, H., Landsberg, J. J., \& Williams, M. 1998. Net primary production of forests: a constant fraction of gross primary production? Tree Physiol., 18, 129-134.

Wall, L., Larocque, D., \& Léger, P.M. 2008. The early explanatory power of NDVI in crop yield modelling. International Journal of Remote Sensing, 29(8), 2211-2225.

Xin, Q.C., Gong, P., Yu, C.Q., Yu, L., Broich, M., Suyker, A.E. \& Myneni, R.B. 2013. A Production Efficiency Model-Based Method for Satellite Estimates of Corn and Soybean Yields in the Midwestern US. Remote Sensing, 5, 5926-5943.

Xu, X.Y., McGrath, S.P., \& Zhao, F.J. 2007. Rapid reduction of arsenate in the medium mediated 
by plant roots. New Phytologist, 176, 590-599.

449

450

451

452

453

Xu, Z.W., Liu, S.M., Li, X., Shi, S.J., Wang, J.M., Zhu, Z.L., Xu, T.R., Wang, W.Z., \& Ma, M.G. 2013. Intercomparison of surface energy flux measurement systems used during the HiWATER-MUSOEXE. Journal of Geophysical Research, 118, 13140-13157.

Yao, X., Zhu, Y., Tian, Y.C., Feng, W., \& Cao, W.X. 2010. Exploring hyperspectral bandsand estimation indices for leaf nitrogen accumulation in wheat. International Journal of Applied Earth Observation and Geoinformation, 12, 89-100.

Yuan, W.P., Liu, S.G., Dong, W.J., Liang, S.L., Zhao, S.Q., \& Chen, J.Q., et al. 2014a. Differentiating moss from higher plants is critical in studying the carbon cycle of the boreal biome. Nature Communications, 5, 4270.

Yuan, W.P., Liu, S.G., Cai, W.W., Liu, S.G., Dong, W.J., Chen, J.Q., et al. 2014b. Are vegetation-specific model parameters required for estimating gross primary production? Ecological Modelling, 292, 1-10.

Yuan, W.P., Liang, S.L., Liu, S.G., Weng, E.S., Luo, Y.Q., Hollinger, D., \& Zhang, H.C. 2012. Improving model parameter estimation using coupling relationships between vegetation production and ecosystem respiration. Ecological Modelling, 240, 29-40.

Yuan, W.P., Liu, S.G., Yu, G.R., Bonnefond, J. -M., Chen, J., Davis, K., et al. 2010. Global estimates of evapotranspiration and gross primary production based on MODIS and global meteorology data. Remote Sensing of Environment, 114, 1416-1431.

Yuan, W.P., Liu, S.G., Zhou, G.S., Zhou, G.Y., Tieszen, L.L., Baldocchi, D., Bernhofer, C., et al. 2007. Deriving a light use efficiency model from eddy covariance flux data for predicting daily gross primary production across biomes. Agricultural and Forest 
471 Yuan, X.F., Wu, P.T., \& Wang, Y.K. 2006. Study on the effect of irrigation under plastic preservation of soil moisture on soil and crop. Journal of Irrigation and Drainage, 25, $21-25$.

474

Zhang, W.L., Chen, S.P., Chen, J., Wei, L., Han, X.G., \& Lin, G.H. 2007. Biophysical regulations of carbon fluxes of a steppe and a cultivated cropland in semiarid Inner Mongolia. Agricultural and Forest Meteorology, 146, 216-229.

477 Zhao, M. S., Heinsch, F. A., Nemani, R. R. \& Running, S. W. 2005. Improvements of the MODIS terrestrial gross and net primary production global data set. Remote Sensing of Environment, 95, 164-176.

480 


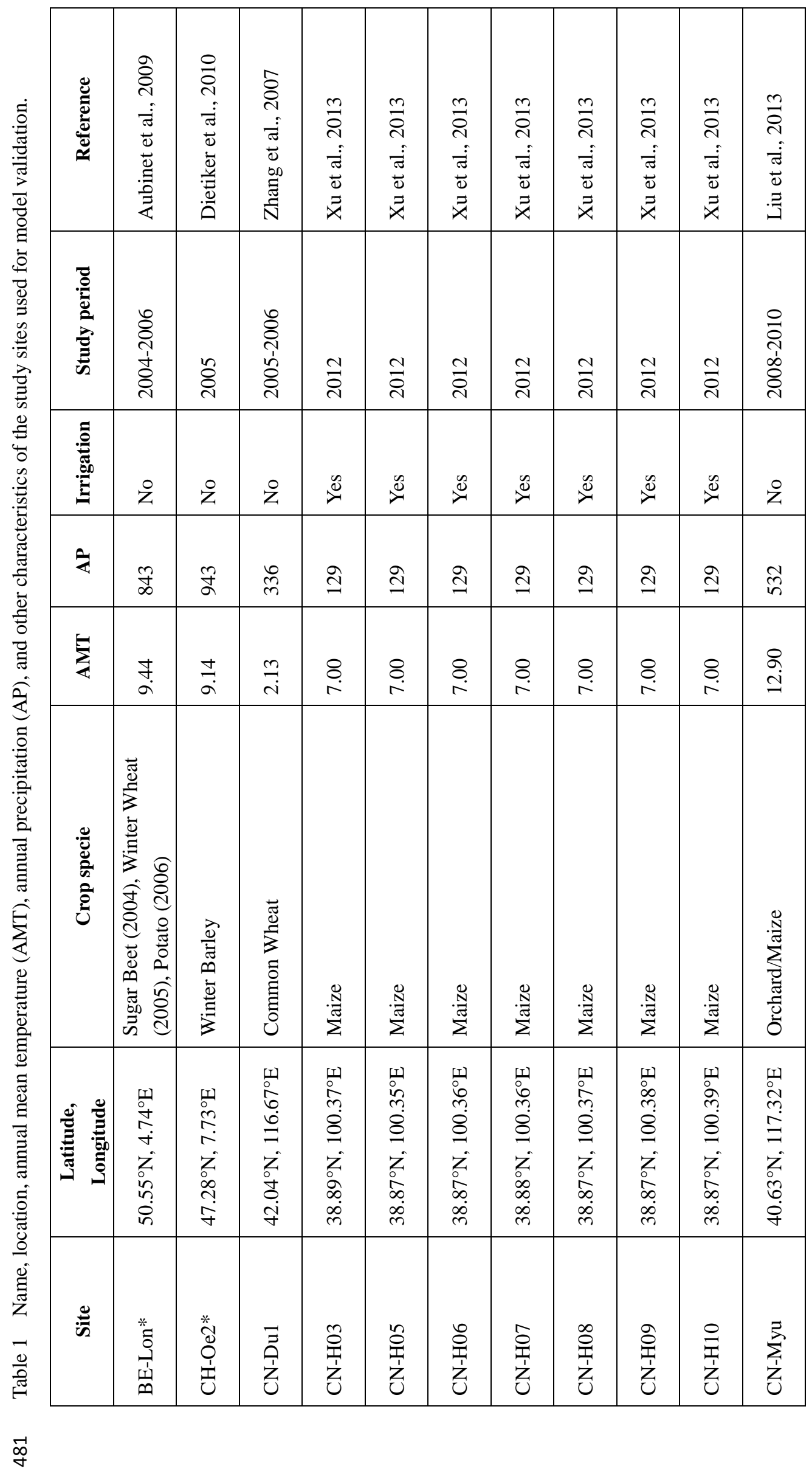




\begin{tabular}{|c|c|c|c|c|c|c|c|c|c|c|c|c|}
\hline 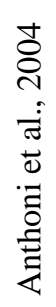 & ' & & ' & ' & 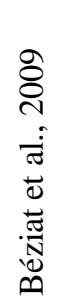 & 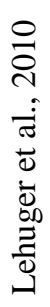 & ' & 1 & 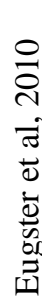 & 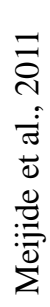 & & \\
\hline 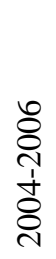 & 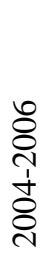 & 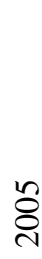 & 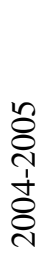 & 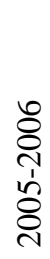 & ஜి & 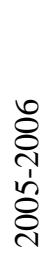 & ஜి & 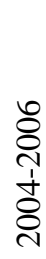 & 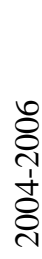 & ஜ্ণ & 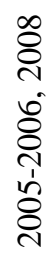 & 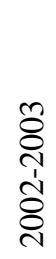 \\
\hline$\stackrel{0}{z}$ & $\approx$ & $\stackrel{\circ}{z}$ & $\stackrel{\infty}{\infty}$ & $\stackrel{\infty}{\nu}$ & z & , & ' & , & $\stackrel{0}{\sigma}$ & $\overbrace{}^{\infty}$ & & $\stackrel{\otimes}{\nu}$ \\
\hline$\stackrel{\mathscr{f}}{f}$ & 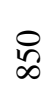 & $\underset{\mathcal{I}}{\sim}$ & $\begin{array}{l}\bar{\infty} \\
i\end{array}$ & ש & $\frac{2}{6}$ & oे & $\stackrel{乛}{\curvearrowright}$ & $\underset{\infty}{\mathbb{N}}$ & $\stackrel{n}{\sim}$ & $\stackrel{\infty}{b}$ & $\underset{ల}{\stackrel{్}{2}}$ & 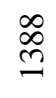 \\
\hline$\underset{\infty}{\stackrel{+}{\infty}}$ & 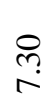 & $\stackrel{?}{r}$ & $\underset{\infty}{\tilde{\infty}}$ & $\stackrel{尺}{\stackrel{尺}{\Xi}}$ & $\begin{array}{l}0 \\
\stackrel{0}{c}\end{array}$ & ָָ & $\begin{array}{l}\vec{b} \\
\dot{j}\end{array}$ & 兑 & $\stackrel{n}{6}$ & 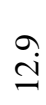 & $\ddot{m}$ & $\stackrel{i n g}{ \pm}$ \\
\hline 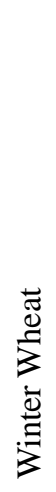 & ' & . & ' & ' & 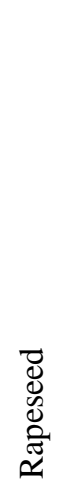 & 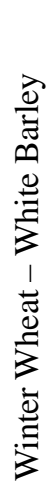 & , & 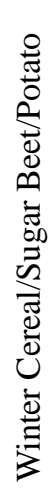 & $\stackrel{\stackrel{\tilde{N}}{\tilde{J}}}{\Sigma}$ & 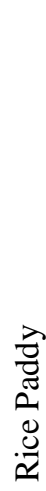 & 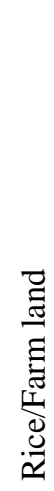 & $\begin{array}{l}\vec{\theta} \\
\frac{\pi}{\pi} \\
0 \\
0 \\
0 \\
0\end{array}$ \\
\hline 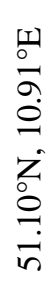 & 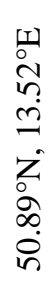 & 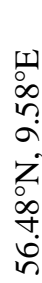 & $\begin{array}{l}\text { In } \\
0 \\
8 \\
\text { in } \\
z \\
z \\
0 \\
n \\
n \\
n \\
n\end{array}$ & 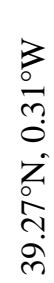 & 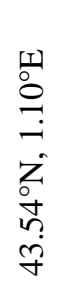 & 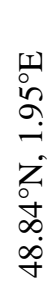 & 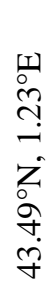 & $\begin{array}{l}3 \\
0 \\
\sigma \\
\sigma \\
z \\
i \\
i \\
\infty \\
i \\
n\end{array}$ & 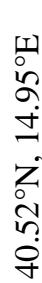 & 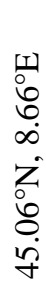 & 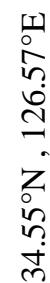 & 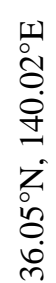 \\
\hline 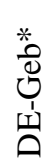 & 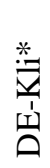 & $\begin{array}{l}* \\
\stackrel{*}{0} \\
\frac{1}{1} \\
\frac{1}{0}\end{array}$ & $\begin{array}{l}\frac{*}{2} \\
\frac{1}{\Delta} \\
\frac{1}{\Delta}\end{array}$ & 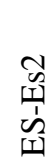 & 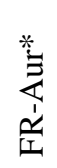 & 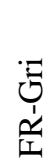 & 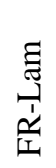 & 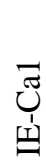 & $\begin{array}{l}\bar{U} \\
\mathscr{\omega} \\
\underline{E}\end{array}$ & 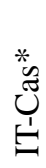 & 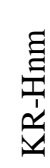 & $\begin{array}{l}\sum_{1}^{J} \\
\stackrel{J}{1}\end{array}$ \\
\hline
\end{tabular}




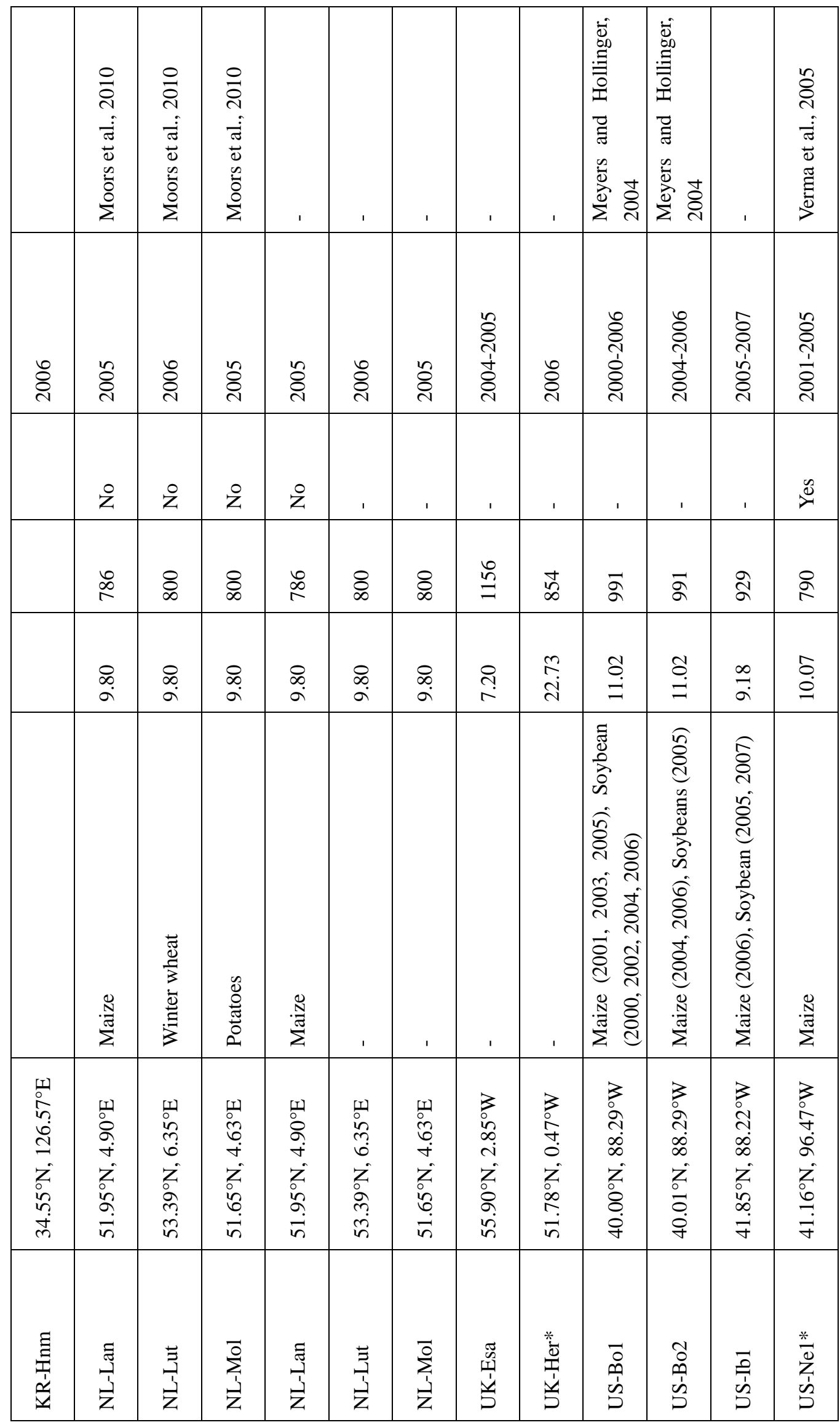




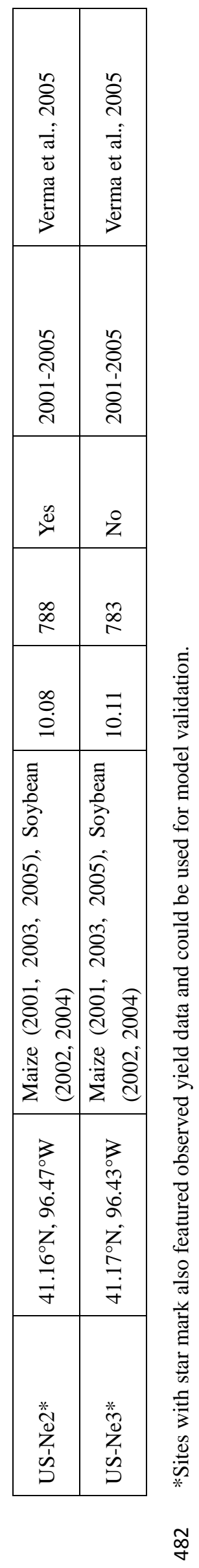


Table 2 Average estimated GPP from EC flux tower data $\left(\mathrm{g} \mathrm{C} \mathrm{m}^{-2}\right.$ day $\left.^{-1}\right)$, average model predicted GPP ( $\mathrm{g} \mathrm{C} \mathrm{m}^{-2}$ day $\left.^{-1}\right)$, and model statistics for all sites under investigation

\begin{tabular}{|c|c|c|c|c|c|}
\hline Site & $\begin{array}{c}\text { Estimated } \\
\text { GPP }\end{array}$ & $\begin{array}{c}\text { Predicted } \\
\text { GPP }\end{array}$ & $\mathbf{R}^{2}$ & RMSE & BIAS \\
\hline BE-Lon & 3.77 & 4.91 & 0.85 & 2.20 & 1.14 \\
\hline $\mathrm{CH}-\mathrm{Oe} 2$ & 6.10 & 7.31 & 0.49 & 3.72 & 1.21 \\
\hline CN-Du1 & 1.58 & 1.61 & 0.77 & 1.13 & 0.03 \\
\hline $\mathrm{CN}-\mathrm{H} 03$ & 12.89 & 15.07 & 0.8 & 2.79 & 2.18 \\
\hline CN-H05 & 13.00 & 14.79 & 0.58 & 3.33 & 1.79 \\
\hline CN-H06 & 15.05 & 15.87 & 0.65 & 4.66 & 0.82 \\
\hline $\mathrm{CN}-\mathrm{H} 07$ & 12.84 & 14.65 & 0.70 & 3.22 & 1.81 \\
\hline $\mathrm{CN}-\mathrm{H} 08$ & 12.99 & 12.92 & 0.58 & 5.00 & -0.07 \\
\hline CN-H09 & 12.60 & 11.64 & 0.72 & 4.51 & -0.96 \\
\hline $\mathrm{CN}-\mathrm{H} 10$ & 14.27 & 16.27 & 0.70 & 3.56 & 2.00 \\
\hline CN-Myu & 1.49 & 1.89 & 0.67 & 0.97 & 0.40 \\
\hline DE-Geb & 5.64 & 4.97 & 0.86 & 2.29 & -0.67 \\
\hline DE-Kli & 5.59 & 5.92 & 0.83 & 2.29 & 0.33 \\
\hline DK-Fou & 5.27 & 6.19 & 0.61 & 2.43 & 0.92 \\
\hline DK-Ris & 5.32 & 5.17 & 0.84 & 2.09 & -0.15 \\
\hline ES-Es2 & 5.32 & 5.17 & 0.84 & 2.09 & -0.15 \\
\hline FR-Aur & 4.20 & 5.23 & 0.85 & 2.04 & 1.03 \\
\hline FR-Gri & 4.38 & 4.45 & 0.87 & 2.08 & 0.07 \\
\hline FR-Lam & 5.01 & 4.64 & 0.81 & 2.14 & -0.37 \\
\hline IE-Ca1 & 3.77 & 2.72 & 0.59 & 3.08 & -1.04 \\
\hline IT-Bci & 12.54 & 13.74 & 0.80 & 3.40 & 1.20 \\
\hline IT-Cas & 9.61 & 7.68 & 0.91 & 4.71 & -1.93 \\
\hline JP-Hfk & 2.52 & 2.43 & 0.69 & 1.36 & -0.09 \\
\hline JP-Mas & 2.14 & 4.03 & 0.47 & 3.37 & 1.89 \\
\hline KR-Hnm & 2.98 & 3.31 & 0.62 & 1.75 & 0.33 \\
\hline NL-Lan & 7.66 & 11.01 & 0.43 & 4.12 & 3.34 \\
\hline NL-Lut & 7.22 & 7.12 & 0.83 & 2.91 & -0.12 \\
\hline
\end{tabular}




\begin{tabular}{|l|c|c|c|c|c|}
\hline NL-Mol & 7.47 & 8.43 & 0.59 & 2.92 & 0.96 \\
\hline UK-Esa & 7.95 & 6.51 & 0.49 & 4.02 & -1.44 \\
\hline UK-Her & 7.62 & 7.71 & 0.86 & 2.73 & 0.09 \\
\hline US-Bo1 Maize & 6.26 & 6.65 & 0.86 & 2.71 & 0.39 \\
\hline US-Bo1 Soybean & 3.89 & 5.29 & 0.83 & 2.82 & 1.39 \\
\hline US-Bo2 Maize & 8.68 & 8.98 & 0.80 & 4.72 & 0.29 \\
\hline US-Ib1 Maize & 6.16 & 6.03 & 0.87 & 3.92 & -0.13 \\
\hline US-Ne1 Maize & 5.69 & 5.36 & 0.92 & 2.30 & -0.33 \\
\hline US-Ne2 Maize & 7.62 & 7.54 & 0.87 & 3.09 & -0.08 \\
\hline US-Ne2 Soybean & 2.69 & 4.54 & 0.91 & 2.93 & 1.84 \\
\hline US-Ne3 Maize & 7.91 & 6.84 & 0.83 & 3.18 & -1.05 \\
\hline US-Ne3 Soybean & 3.14 & 5.05 & 0.92 & 2.83 & 1.91 \\
\hline
\end{tabular}

483 
484

485

486

487

488

489

490

491

492

493

494

495

496

497

498

499

500

501

502

503

504

\section{Figure captions}

Figure 1 Daily variation of EC-LUE model predicted (black solid lines) and estimated (open

circle dots) GPP at all study sites. The x-axis indicates the day of the year at CN-He3, CN-He5,

CN-He6, CN-He7, CN-He8, CN-He9 and CN-He10, since only one season data was available at these sites.

Figure 2 Average predicted GPP from the EC-LUE and estimated GPP from the EC measurements for various crop species. The dashed line is a 1:1 line. The solid red and black lines are linear regression lines with a revised C4 crop parameter $\left(y=0.98 x+0.55, R^{2}=0.90\right)$ and original model parameter $\left(y=0.67 x+1.64, R^{2}=0.82\right)$, respectively.

Figure 3 Predicted GPP from the EC-LUE and estimated GPP from the EC measurements for all study sites in Table 1 . The short dashed line is a 1:1 line and the solid line is a linear regression line.

Figure 4 Predicted and observed crop yield at 12 sites (see Table 1). The short dashed line is a 1:1 line and the solid line is a linear regression line. (a) Estimated yield based on the simulated GPP of EC-LUE model; (b) estimated yield based on the estimated GPP using EC measurements.

Figure 5 Ratio of observed GPP and yield between irrigated and rainfed maize (a) and soybean (b) at the US-NE2 and US-NE3 FLUXNET sites 

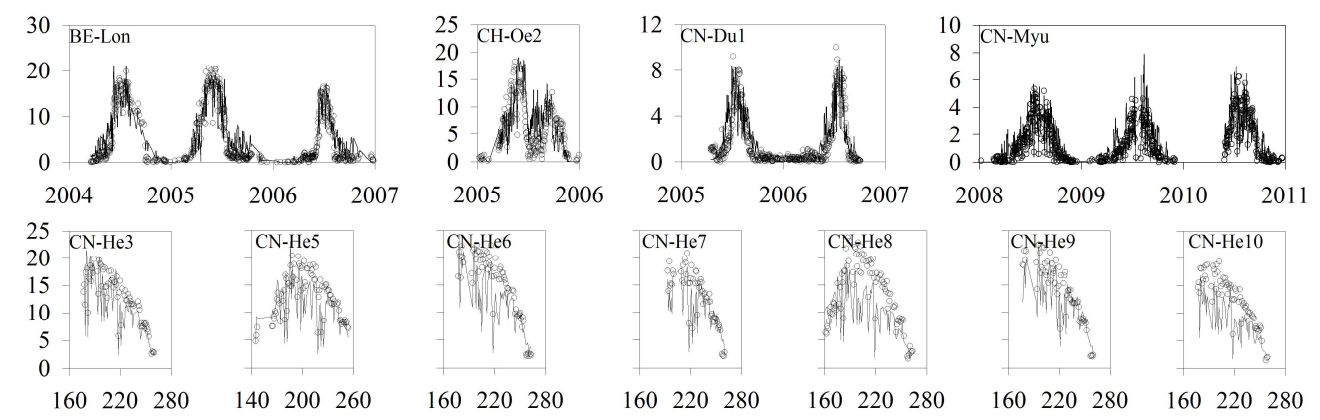

$\begin{array}{lll}160 & 220 \quad 280\end{array}$

160220280

$\begin{array}{llllll}160 & 220 & 280 & 160 & 220 & 280\end{array}$
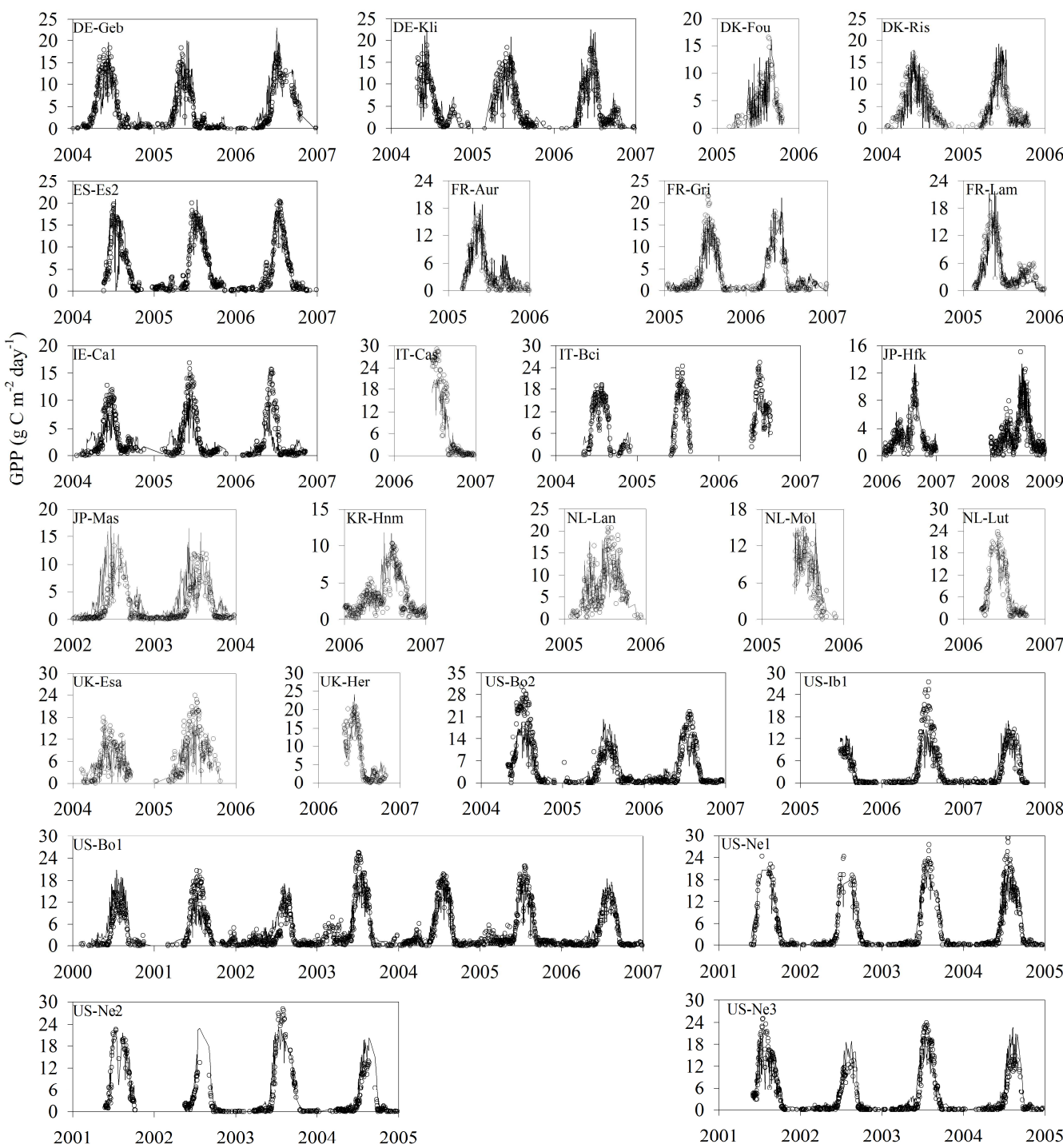

Figure 1 Daily variation of EC-LUE model predicted (black solid lines) and estimated (open circle dots) GPP at all study sites.. The $\mathrm{x}$-axis indicates the day of the year at $\mathrm{CN}-\mathrm{He} 3, \mathrm{CN}-\mathrm{He} 5$, $\mathrm{CN}-\mathrm{He} 6, \mathrm{CN}-\mathrm{He} 7, \mathrm{CN}-\mathrm{He} 8, \mathrm{CN}-\mathrm{He} 9$ and $\mathrm{CN}-\mathrm{He} 10$, since only one season data was available at 


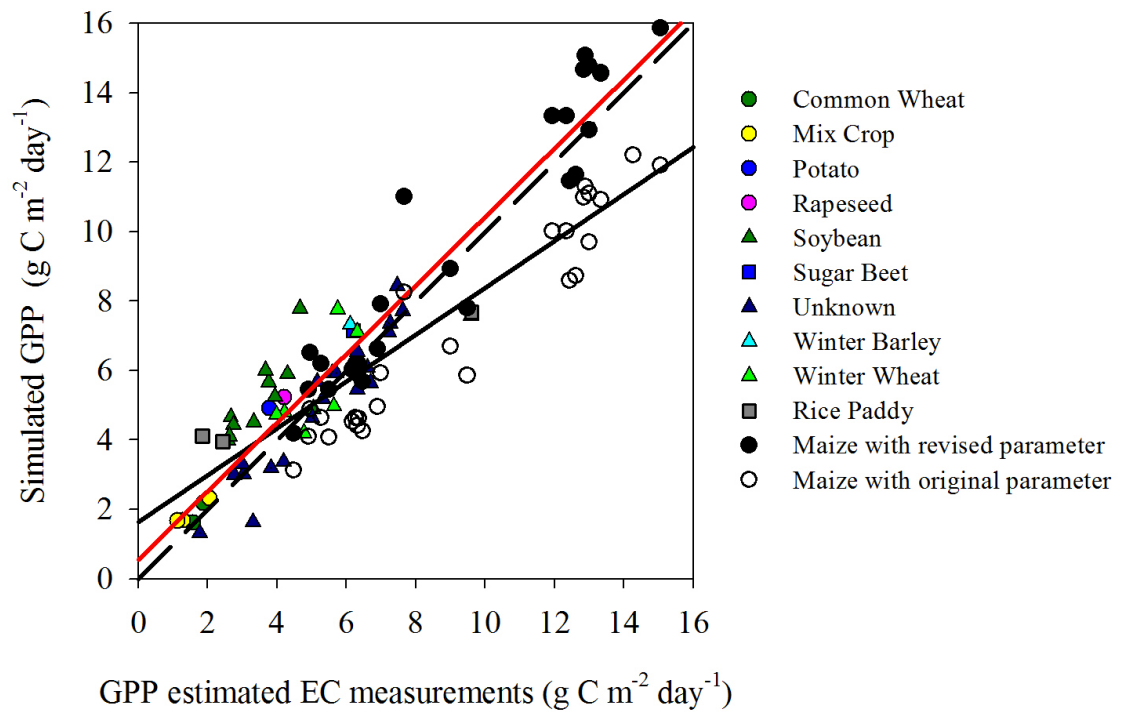

Figure 2 Average predicted GPP from the EC-LUE and estimated GPP from the EC

512 measurements for various crop species. The dashed line is a 1:1 line. The solid red and black lines

513 are linear regression lines with a revised $C 4$ crop parameter $\left(y=0.98 x+0.55, R^{2}=0.90\right)$ and

$514 \quad$ original model parameter $\left(y=0.67 x+1.64, R^{2}=0.82\right)$, respectively. 


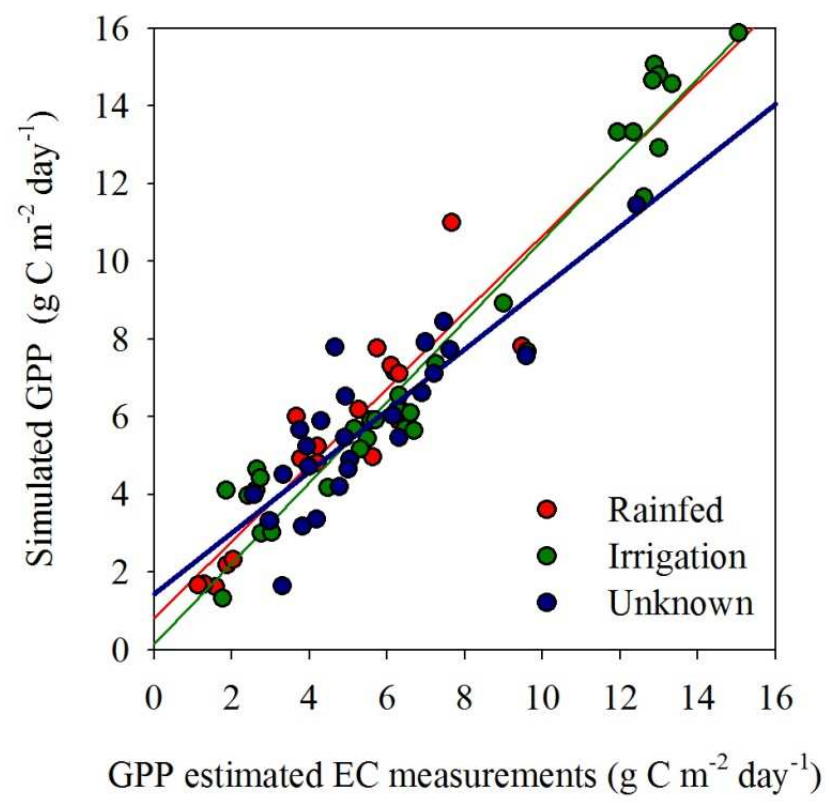

516 Figure 3 Predicted GPP from the EC-LUE and estimated GPP from the EC measurements for all

517 study sites in Table 1. The short dashed line is a 1:1 line and the solid line is a linear regression line. 


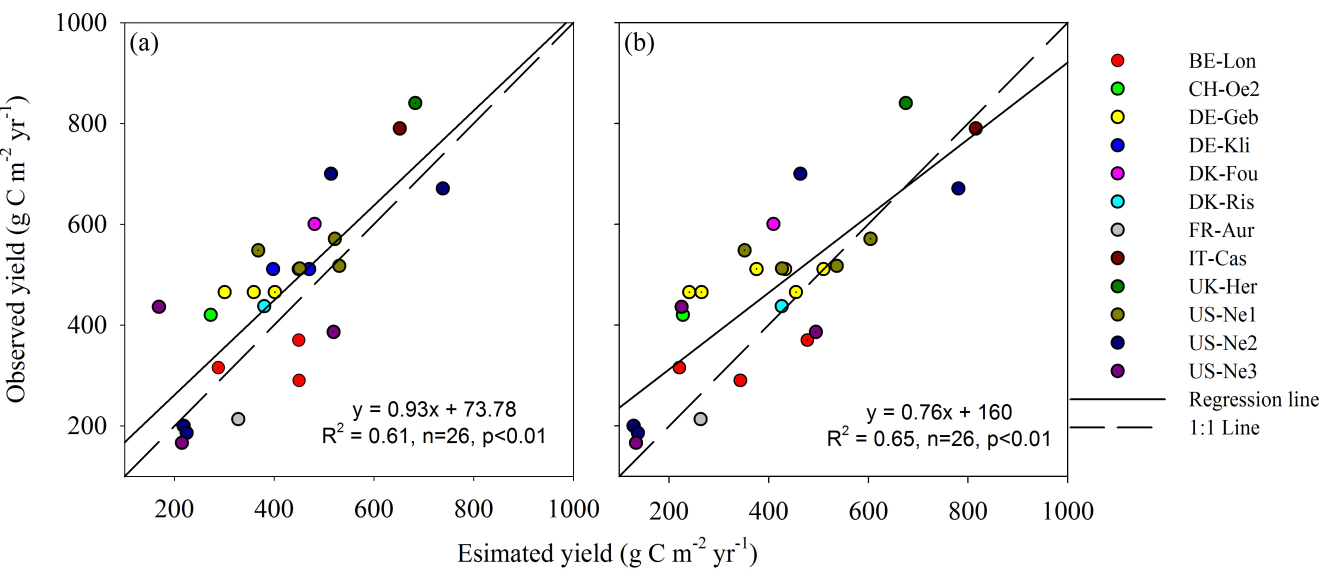

520 Figure 4 Predicted and observed crop yield at 12 sites (see Table 1). The short dashed line is a

$521 \quad 1: 1$ line and the solid line is a linear regression line. (a) Estimated yield based on the simulated

522 GPP of EC-LUE model; (b) estimated yield based on the estimated GPP using EC measurements. 

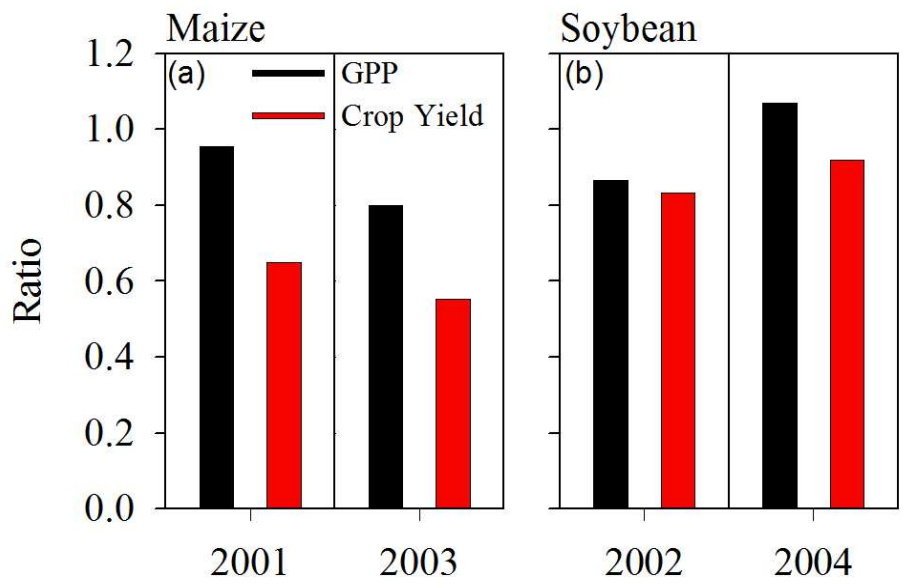

523

524 Figure 5 Ratio of observed GPP and yield between irrigated and rainfed maize (a) and soybean

(b) at the US-NE2 and US-NE3 FLUXNET sites. 
Figure 1
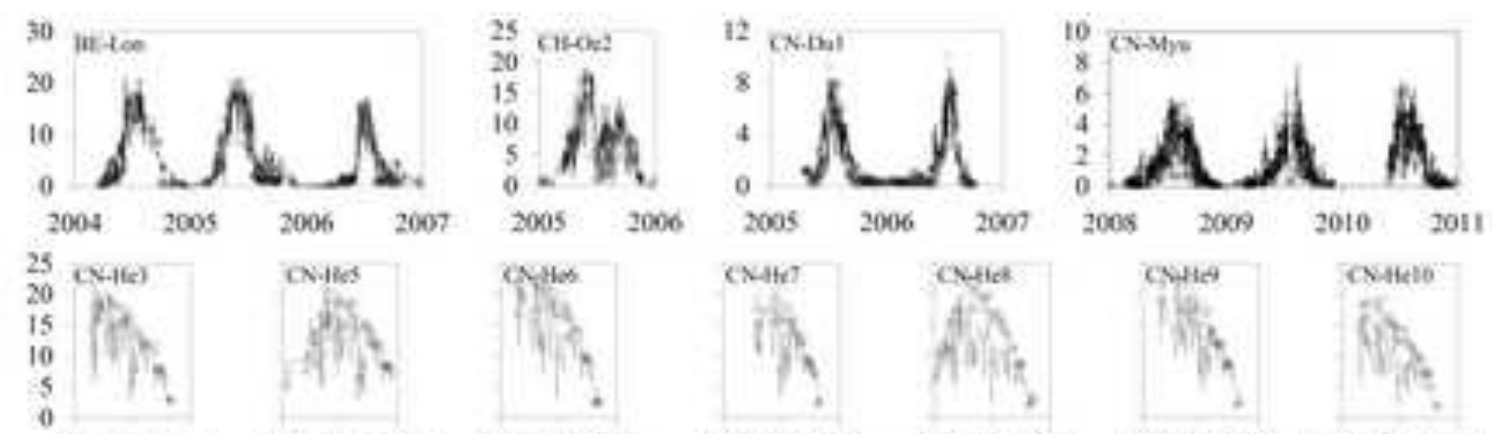

crateio
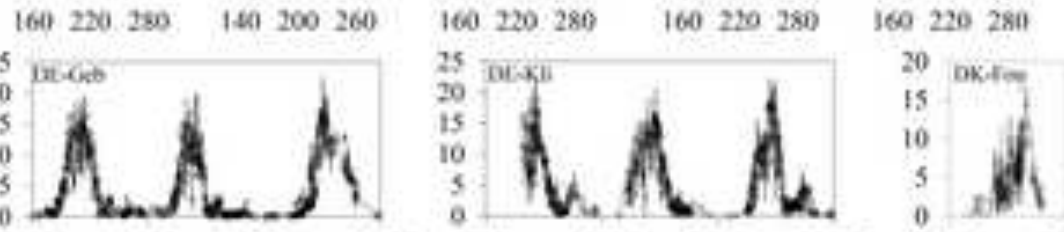

$160220280 \quad 160220260$
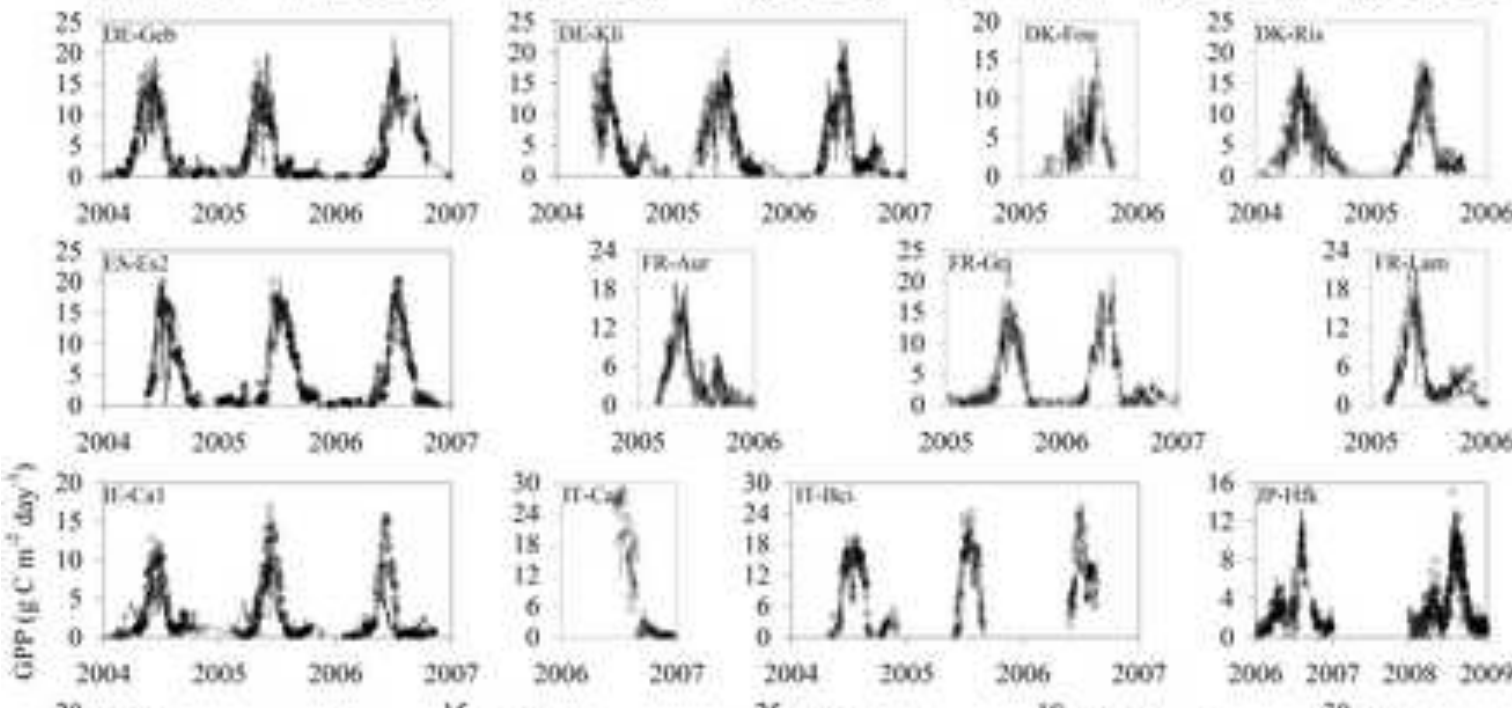

2006
$30.71 \cdot 14$

Do0s $2006 \quad 2007$
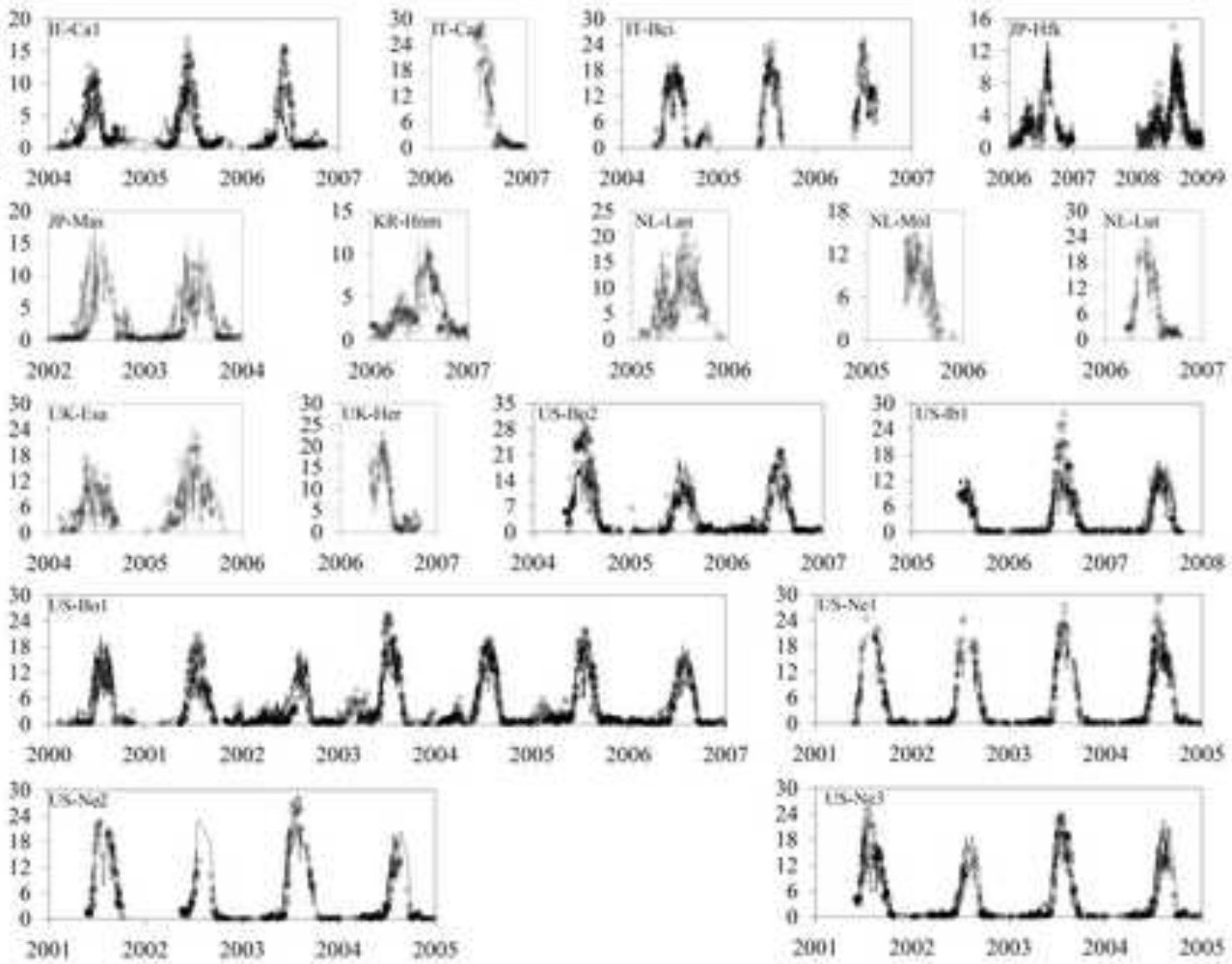

Time 


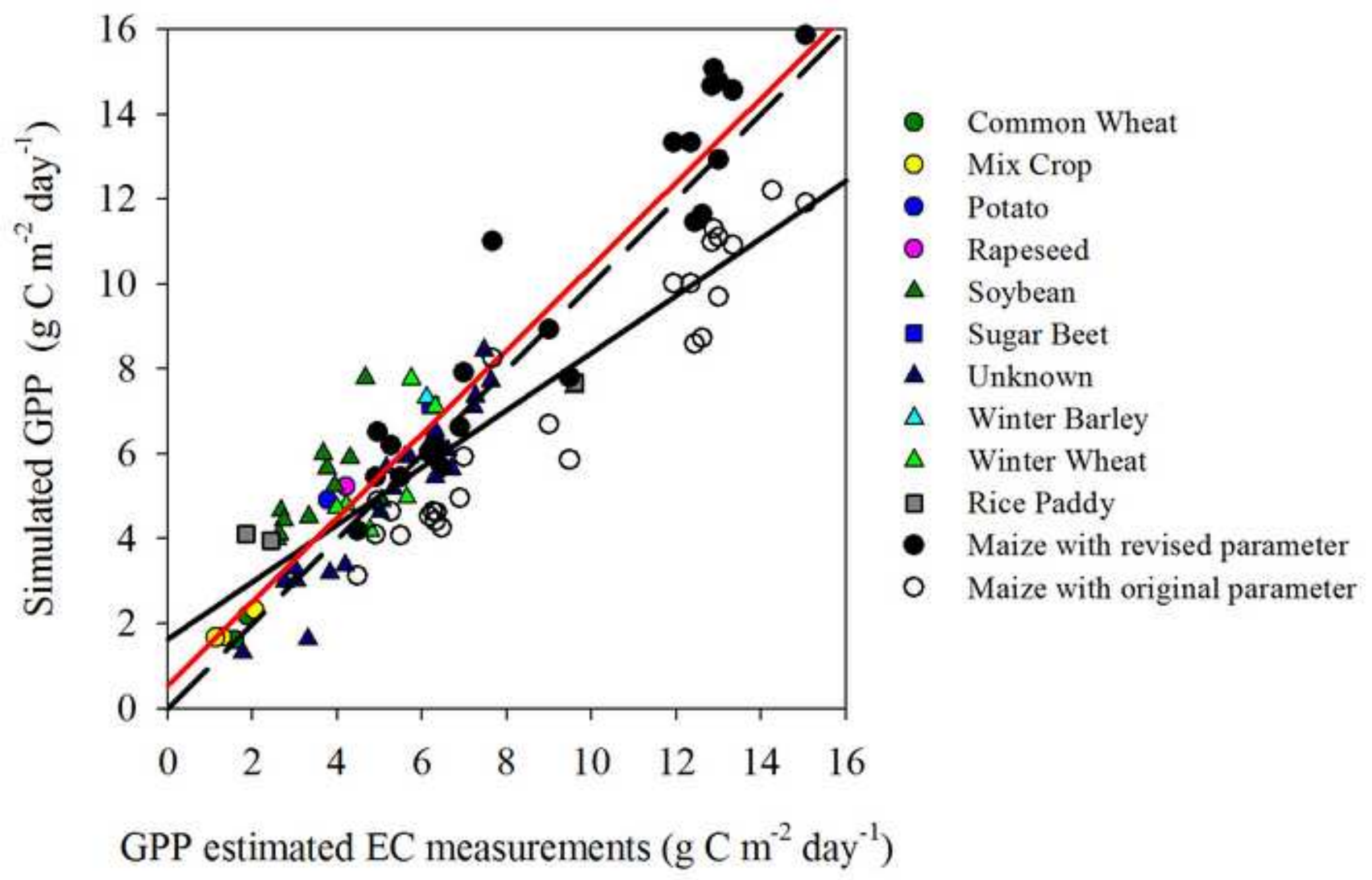




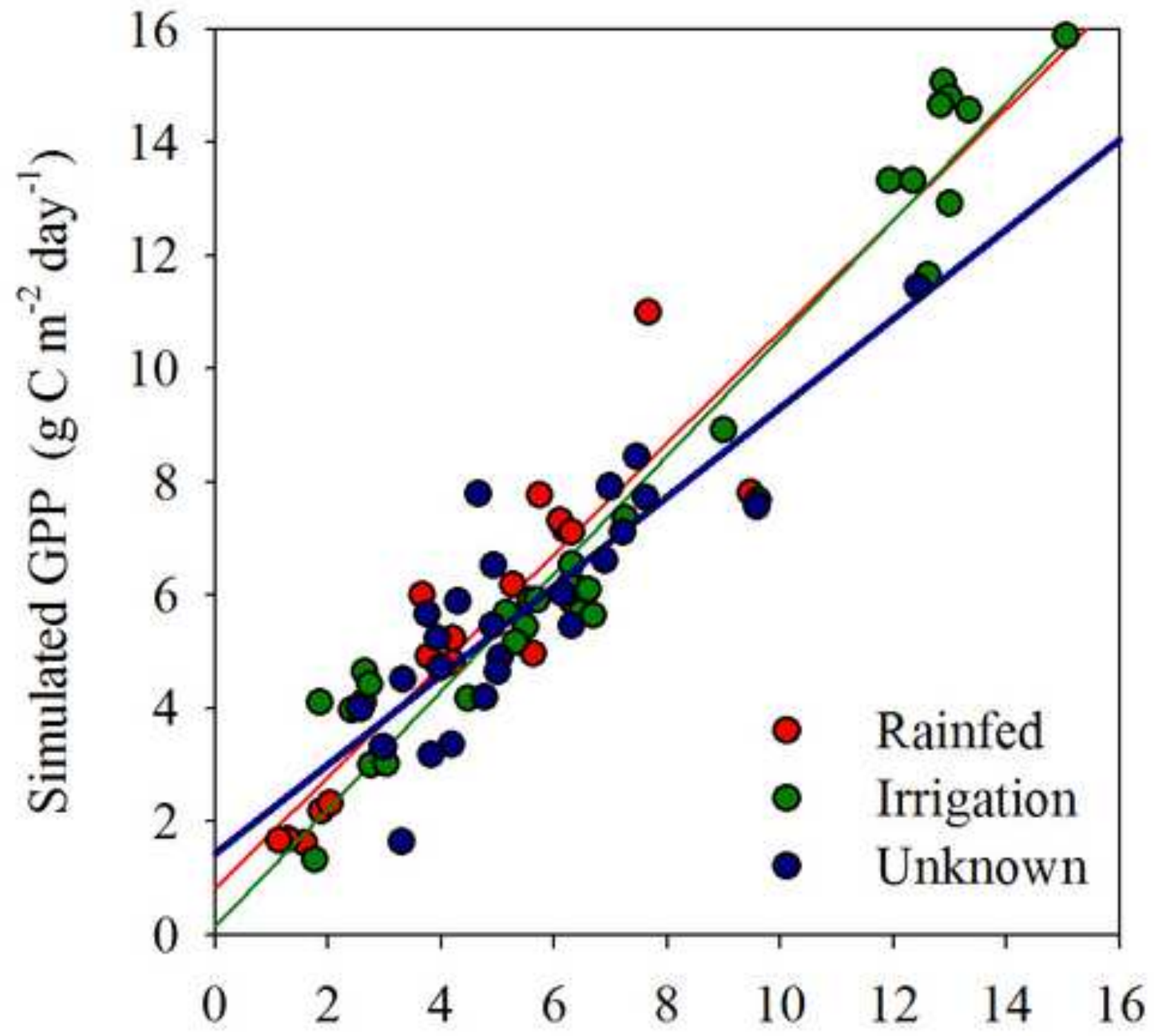

GPP estimated EC measurements $\left(\mathrm{g} \mathrm{C} \mathrm{m}^{-2}\right.$ day $\left.^{-1}\right)$ 


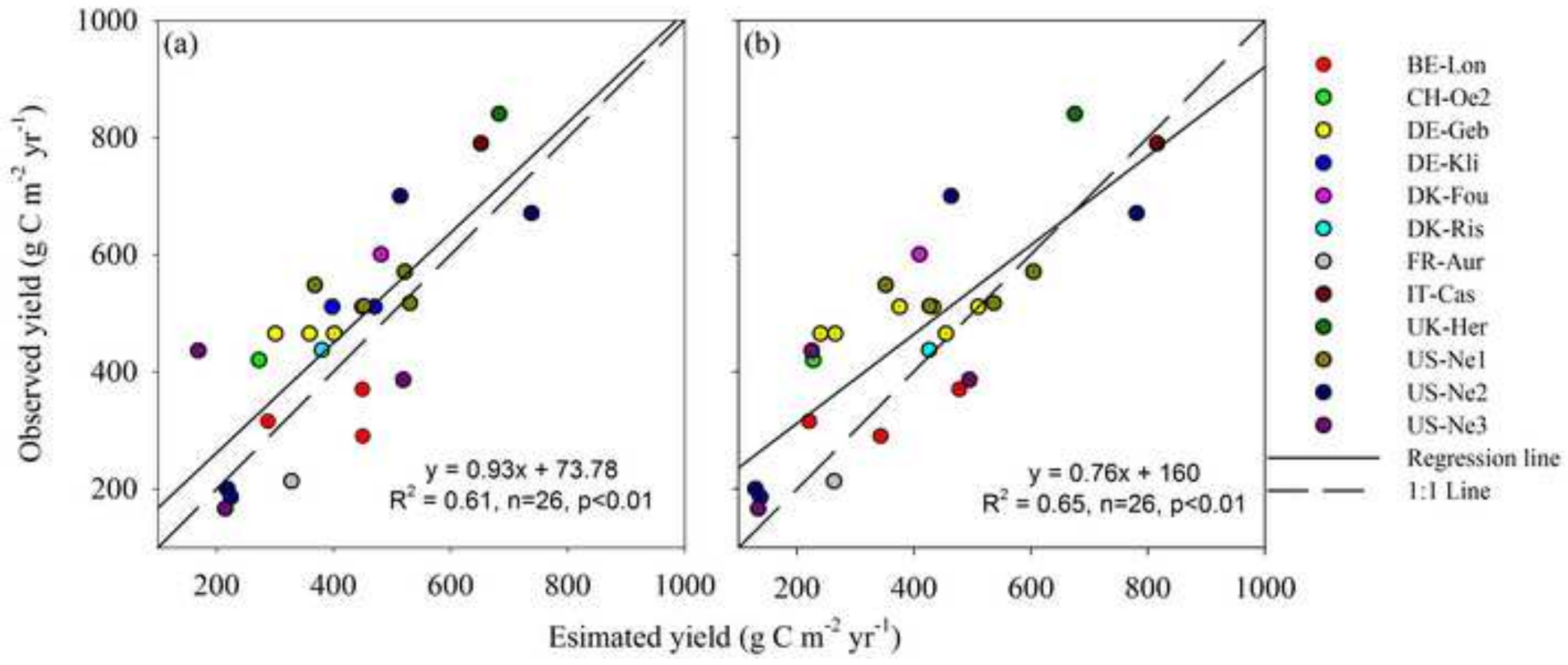



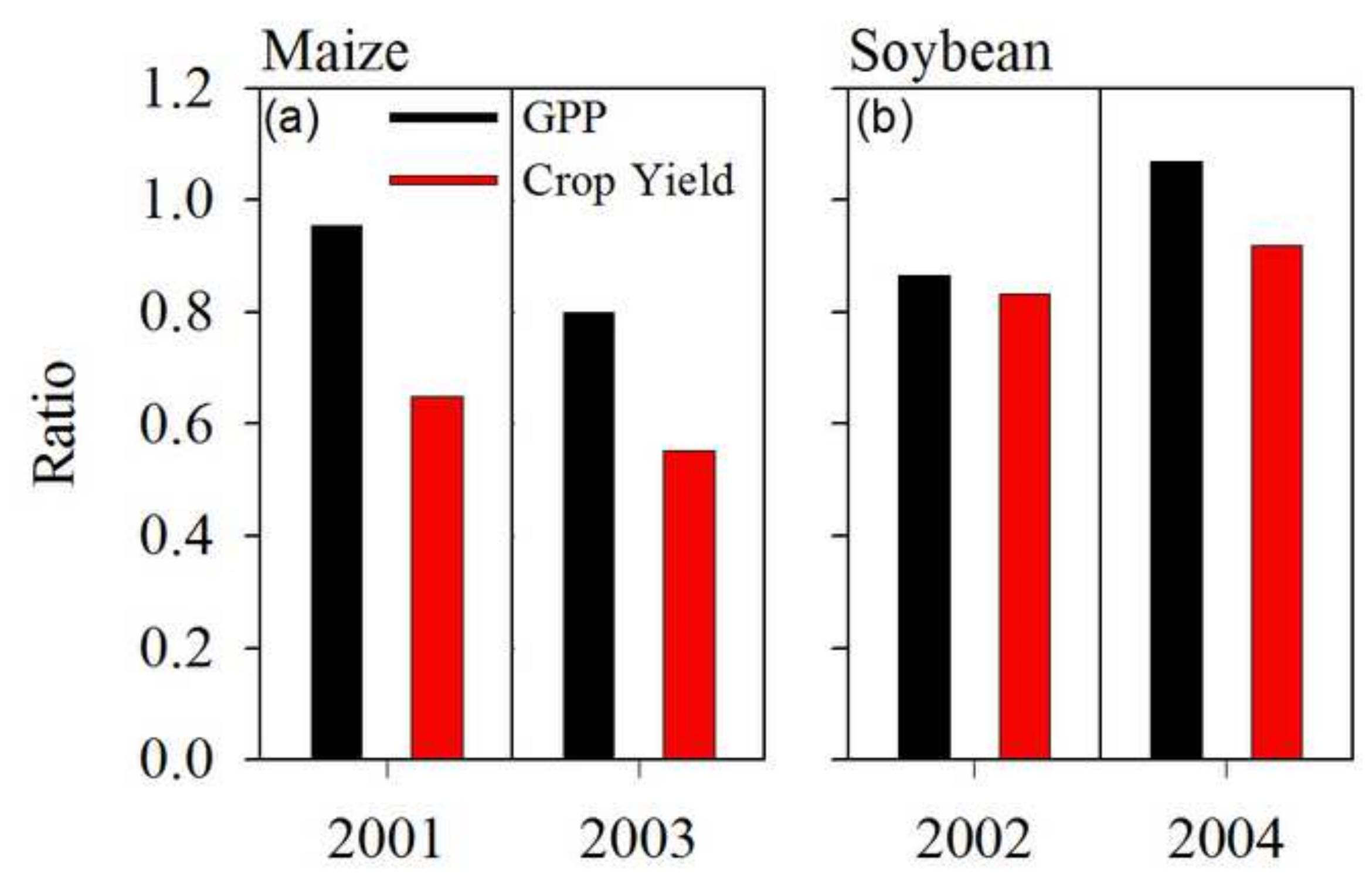